\title{
Ribonuclease E provides substrates for ribonuclease P-dependent processing of a polycistronic mRNA
}

\author{
Pietro Alifano, Flavia Rivellini, Claudia Piscitelli, Cecilia M. Arraiano, ${ }^{1}$ Carmelo B. Bruni, and \\ M. Stella Carlomagno \\ Centro di Endocrinologia ed Oncologia Sperimentale del Consiglio Nazionale delle Ricerche, Dipartimento di Biologia \\ e Patologia Cellulare e Molecolare "L. Califano," Università degli Studi di Napoli, Via S. Pansini 5, 80131 Napoli, Italy
}

The polycistronic mRNA of the histidine operon is subject to a processing event that generates a rather stable transcript encompassing the five distal cistrons. The molecular mechanisms by which such a transcript is produced were investigated in Escherichia coli strains carrying mutations in several genes for exo- and endonucleases. The experimental approach made use of $S 1$ nuclease protection assays on in vivo synthesized transcripts, site-directed mutagenesis and construction of chimeric plasmids, dissection of the processing reaction by RNA mobility retardation experiments, and in vitro RNA degradation assays with cellular extracts. We have found that processing requires (1) a functional endonuclease $E_{;}(2)$ target site(s) for this activity in the RNA region upstream of the $5^{\prime}$ end of the processed transcript that can be substituted by another well-characterized rne-dependent cleavage site; (3) efficient translation initiation of the first cistron immediately downstream of the $5^{\prime}$ end; and (4) a functional endonuclease $P$ that seems to act on the processing products generated by ribonuclease $E$. This is the first evidence that ribonuclease $P$, an essential ribozyme required for the biosynthesis of tRNA, may also be involved in the segmental stabilization of a mRNA.

[Key Words: Escherichia coli; Salmonella typhimurium; his operon; mRNA processing; translation; RNase E; RNase P]

Received June 2, 1994; revised version accepted October 18, 1994.

mRNA decay in bacteria is mediated by the coordinated action of exonucleases and endonucleases (for review, see Petersen 1992). Polynucleotide phosphorylase (PNPase) and ribonuclease II (RNase II) are the two major $3^{\prime} \rightarrow 5^{\prime}$ exonucleases involved in mRNA turnover (Donovan and Kushner 1986). Endoribonuclease III (RNase III) does not affect bulk mRNA stability (Babitzke et al. 1993) and is mostly involved in processing of the 30S rRNA precursor even though RNase III can initiate the functional decay of a few specific mRNAs (Court 1993). Endoribonuclease E (RNase E) was initially characterized as the enzyme that processes the precursor of 5S rRNA (Ghora and Apirion 1978). RNase E is the only endoribonuclease implicated thus far in general mRNA turnover (Arraiano et al. 1988; Mudd et al. 1990b; Babitzke and Kushner 1991). Many mRNAs were shown to contain sites whose cleavage was abolished in strains harboring temperature-sensitive rne mutations at the nonpermissive temperature (Kokoska et al. 1990; Mudd et al. 1990a; Gross 1991; Lin-Chao and Cohen 1991; Nilsson and Uhlin 1991; Régnier and Hajnsdorf

${ }^{1}$ Instituto de Tecnologia Quìmica e Biològica, Università Nova Lisboa, 2780 Oeiras, Portugal.
1991; Patel and Dunn 1992; Arraiano et al. 1993; Klug 1993; Mudd and Higgins 1993; Carpousis et al. 1994). rne-dependent cleavages might produce relatively stable processed transcripts, such as the T4 gene 32 (Mudd et al. 1988) and the dicF (Faubladier et al. 1990) and the gltX mRNAs (Brun et al. 1990). In different studies ribonuclease P (RNase P) and other nucleases responsible for stable RNA processing did not seem to be involved in mRNA degradation (Deutscher 1988).

We have previously identified in Salmonella typhimurium a rather stable 3900-nucleotide-long mRNA molecule derived by specific maturation of the his operon primary transcript. This species spans the five distal cistrons of the histidine gene cluster, and its formation requires a cis-acting element located 620 nucleotides upstream of the $5^{\prime}$ end of the processed species and the presence of initiating ribosomes at the intercistronic barrier his $C /$ his $B$ located immediately downstream (Alifano et al. 1992).

We have now studied the molecular mechanisms of this specific processing in several exo- and endoribonuclease mutant strains of Escherichia coli. We have demonstrated that processing is reduced in RNase E mutants and that in the presence of nonfunctional exonucleolytic 
activities several rne-dependent cleavages are detected in the region spanning the cis-acting element. We have also shown that a well-characterized rne-dependent cleavage site can substitute for the element. The formation of the $5^{\prime}$ end of the 3900-nucleotide species is impaired in RNase P mutants both in in vivo and in vitro assays. Additional in vivo evidence obtained confirmed the role of initiating ribosomes at the his $B$ start site in the processing reaction. These observations are consistent with a processing model in which cleavage by RNase $\mathrm{P}$ of rne-dependent endonucleolytic products stabilizes the distal part of a polycistronic transcript.

\section{Results}

The processed 3900-nucleotide-long RNA derived from the primary transcript of the his operon of $S$. typhimurium is the most abundant species in the steady-state mRNA samples and has a half-life of 15 min compared with a half-life of $\sim 2 \mathrm{~min}$ for the full-length transcript. The transcription pattern of the his operon in E. coli is indistinguishable from the one in $S$. typhimurium, including the processed species (Carlomagno et al. 1988; Alifano et al. 1992). We have therefore used as an experimental system the $S$. typhimurium-derived plasmid pUH1293, which contains all of the elements necessary for the processing event within hisC (Fig. 1A; Alifano et al. 1992). The different $E$. coli strains (Table 1) were transformed with this plasmid. Total RNA extracted from transformed strains was hybridized to a 5 '-end-labeled 612-bp $S$. typhimurium-specific HindIII fragment spanning the $5^{\prime}$ end of the 3900-nucleotide processed species (Fig. 1A, shaded area; Fig. 2, lane 1). This probe does not cross-hybridize to his-specific $E$. coli transcripts (Materials and methods). The hybrids were digested with S1 nuclease and analyzed on $5 \%$ polyacrylamide-urea denaturing gel. The same product corresponding to the $5^{\prime}$ end of the processed transcript $(\alpha ;$ Fig. 1B) was detected in RNA samples from $S$. typhimurium wild-type strain LT2 (Fig. 2, lane 2) or from E. coli strain SK5006 harboring the pUH1293 plasmid (Fig. 2, lane 3). This cleavage site is located 76 nucleotides upstream of the AUG initiation codon of the hisB cistron (Fig. 1B).

\section{RNase E mutants show reduced endonucleolytic- specific cleavages}

The RNase-deficient strains SK5003 (pnp7 rnb500) and SK5721 (pnp7 rnb500 rne1) harboring pUH1293 were grown at $30^{\circ} \mathrm{C}$ to early logarithmic phase. One-half of the culture was then shifted to $44^{\circ} \mathrm{C}$ for $40 \mathrm{~min}$ before harvesting the cells for RNA isolation (see Materials and

A

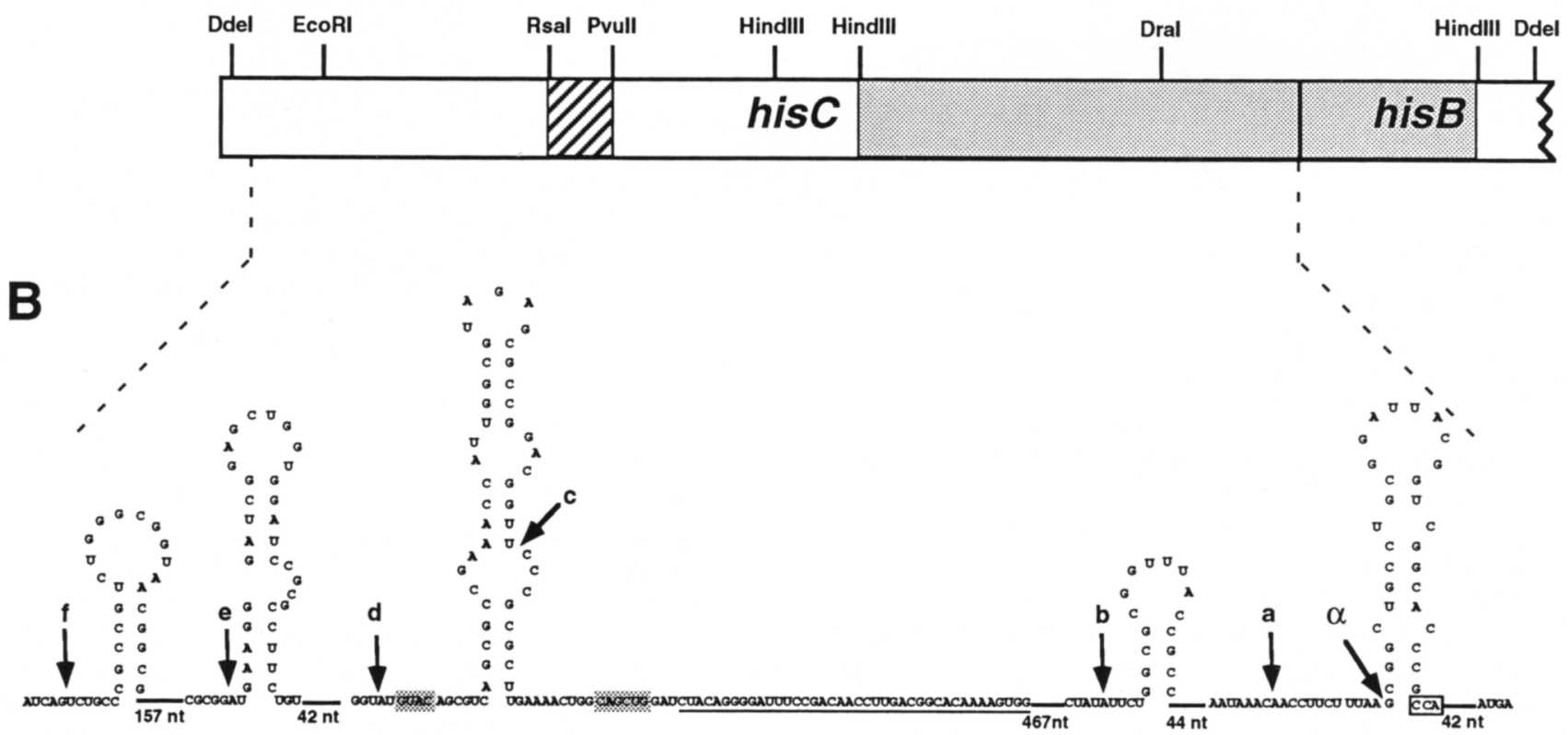

Figure 1. A Physical and genetic map of the his $C B$ region of the his operon of $S$. typhimurium. The DdeI fragment cloned in plasmid pUH1293 and relevant restriction sites are shown. The shaded area indicates the 612-bp HindIII fragment used as a probe in S1 protection experiments. The hatched area indicates the fragment spanning the upstream cis-acting element required for processing. $(B)$ Secondary structures and relevant sequences in the processed region. The arrows indicate the multiple me-dependent cleavages $(\mathbf{f}-\mathbf{a})$ and the rnp-dependent cleavage $(\alpha)$ that corresponds to the $5^{\prime}$ end of the processed species. The CCA consensus at the 3 ' end of the hairpin (Forster and Altman 1990) is boxed. The RsaI and PvuIl restriction sites that delimit the cis-acting element are shaded. The region complementary to the primer used in the degradation assays (Fig. 3) is underlined. At the 3 ' end of the sequence is the hisC/hisB intercistronic barrier. 
Table 1. Bacterial strains

\begin{tabular}{|c|c|c|}
\hline Strain & Genotype & Reference \\
\hline \multicolumn{3}{|c|}{ S. typhimurium } \\
\hline LT2 & wild type & Rechler et al. (1972) \\
\hline \multicolumn{3}{|l|}{ E. coli } \\
\hline SK5006 & $\begin{array}{l}\text { thr leu, pDK39 } \\
\left(\mathrm{Cm}^{\mathrm{r}} \mathrm{rnb} 500\right)\end{array}$ & Arraiano et al. (1988 \\
\hline SK5003 & $\begin{array}{l}\text { SK5006 pnp } 7 \\
\text { mb500 }\end{array}$ & Arraiano et al. 1988 \\
\hline SK5721 & $\begin{array}{l}\text { SK5006 rne1 pnp7 } \\
\quad \text { rnb500 }\end{array}$ & Arraiano et al. (1988 \\
\hline SK5695 & SK5006 rne1 & Arraiano et al. (1988 \\
\hline BF265 & $\begin{array}{l}\arg \text { gly try } \\
\quad \text { lacZ(Am) } \mathrm{Sm}^{\mathrm{r}}\end{array}$ & Kole et al. $(1980)$ \\
\hline A49 & BF265 rnpA49 & Kole et al. $(1980)$ \\
\hline 4273 & $\begin{array}{c}\operatorname{lac} Z(\mathrm{Am}) \mathrm{T} 6^{\mathrm{r}}(\mathrm{Am}) \\
\mathrm{BF} 23^{\mathrm{r}}(\mathrm{Am}) s u^{-}\end{array}$ & Kole et al. (1980) \\
\hline ts 709 & $4273 \mathrm{rnpB} 709$ & Kole et al. (1980) \\
\hline HT115 & $\operatorname{mc} 14:: \Delta \operatorname{Tn} 10$ & Takiff et al. (1989) \\
\hline
\end{tabular}

methods). Strain SK5003 has an inactive pnp allele (Reiner 1969) and a rnb(Ts) mutation and produces only a partially temperature-sensitive RNase II enzyme (Donovan and Kushner 1986). Compared with SK5006, the exonucleases-deficient SK5003 strain accumulated intermediate breakdown products ( $\mathrm{a}$ and $\mathrm{b}$ in Fig. $1 \mathrm{~B}$ ) and showed an increase of the processed species $\langle\alpha\rangle$ at both temperatures (Fig. 2, lanes 4,5). In addition to pnp and $r n b(t s)$ mutations, strain SK5721 harbors a temperaturesensitive rne1 mutation (Arraiano et al. 1988). When grown at $30^{\circ} \mathrm{C}$, this strain had a profile similar to SK5003 (Fig. 2, lane 7). However, when strain SK5721 was shifted to $44^{\circ} \mathrm{C}$, the protection pattern was different. The amount of the $\alpha, a$, and b species was reduced, whereas the amount of full-length protected fragment was increased (Fig. 2, lane 6). These data suggest that the processing event leading to formation of the 3900-nucleotide species is rne dependent.

The upstream cis-acting element contains RNase $E$ target sites and can be replaced by a functionally equivalent element

The genetic evidence that the processed species is generated by an rne-dependent mechanism (Fig. 2) led us to pursue more direct evidence using in vitro experiments. We have reported previously that processing requires an upstream cis-acting element within hisC (Fig. 1A, hatched region) that binds soluble factors in a mobility retardation assay (Alifano et al. 1992). This element was able to bind components present in an RNase E-enriched fraction and wild-type but not rne1-derived extracts (data not shown).

A single processed species ( $\alpha$ in Fig. 2) was present in the parental strain, whereas other intermediates could only be detected in exoribonuclease-defective hosts (a and $b$ in Fig. 2). The relative position of the $5^{\prime}$ ends of the $\mathrm{a}$ and $\mathrm{b}$ rne-dependent intermediates was deduced from sequence ladders run in parallel (data not shown). They map upstream but in close proximity to the $5^{\prime}$ end of the processed species $\langle\alpha\rangle$ and quite 3 '-distal to the cis-acting element (Fig. 1B). This suggests that other unstable exoribonucleases-sensitive breakdown products could be present but not detectable with the SI protection assay.

To detect additional endonucleolytic cleavages, we extended our analysis to the sequences surrounding the cis-acting element by an in vitro degradation assay. A cold RNA was obtained in vitro by runoff transcription of the recombinant linearized plasmid pGEM1293 (Materials and methods). This cold transcript was incubated at $44^{\circ} \mathrm{C}$ for $5 \mathrm{~min}$ with $\mathrm{S} 30$ extracts obtained from strains SK5003 (pnp7 rnb500) and SK5721 (pnp7 rnb500 rne1) shifted to $44^{\circ} \mathrm{C}$ for $40 \mathrm{~min}$. A $5^{\prime}$-end-labeled 40 -nucleotide-long DNA primer (Fig. 3, lane 5), complementary to the region immediately downstream from the cis-acting element (Fig. 1B, underlined), was annealed to the breakdown products and elongated with reverse transcriptase. The complementary DNA obtained from the untreated runoff RNA is a ladder of nonspecific degradation products and/or premature transcription stops, including some full-length molecules (Fig. 3, lane 1). After incubation of the RNA with the extract derived from strain SK5003, several bands were detected above background, four of which were most prominent (c-f in Fig. 3, lane 2). These intermediate products were reduced when

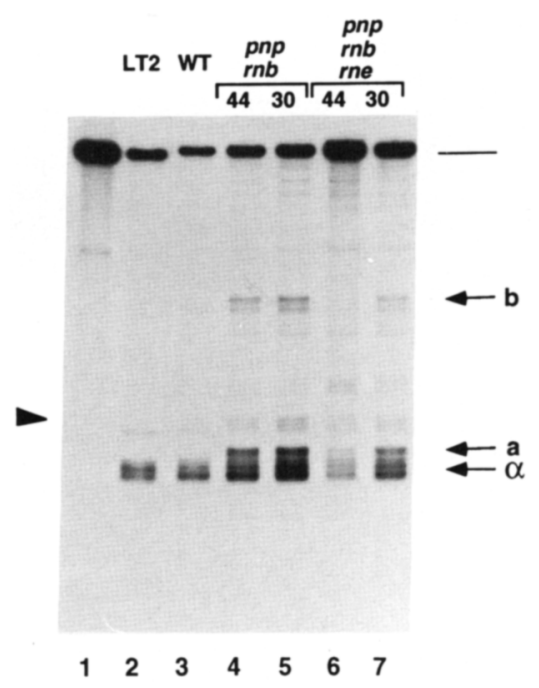

Figure 2. Formation of the 3900-nucleotide species is rne dependent. The probe (Fig. 1A) labeled at its $5^{\prime}$ end (lane 1) was hybridized to $20 \mu \mathrm{g}$ of total RNA extracted from wild-type $S$. typhimurium strain LT2 (lane 2), from E. coli strain SK5006 harboring the pUH1293 plasmid (WT) (lane 3), from strains SK5003 (pnp rnb) and SK5721 (pnp rnb rne) carrying the same plasmid and grown at $30^{\circ} \mathrm{C}$ (lanes 5 and 7 , respectively) or shifted to $44^{\circ} \mathrm{C}$ (lanes 4 and 6 , respectively). Hybrids were treated with $\mathrm{Sl}$ nuclease, and the DNA protected fragments were analyzed on a $5 \%$ polyacrylamide-urea denaturing gel. The bar indicates the full-length protected hybrids, and the arrows the $5^{\prime}$ ends of the hybrids $(b, a$, and $\alpha)$ sensitive to inactivation of the rne locus. The arrowhead at left indicates the hybrid formed by transcripts initiating at the internal P2 promoter (Alifano et al. 1992). 


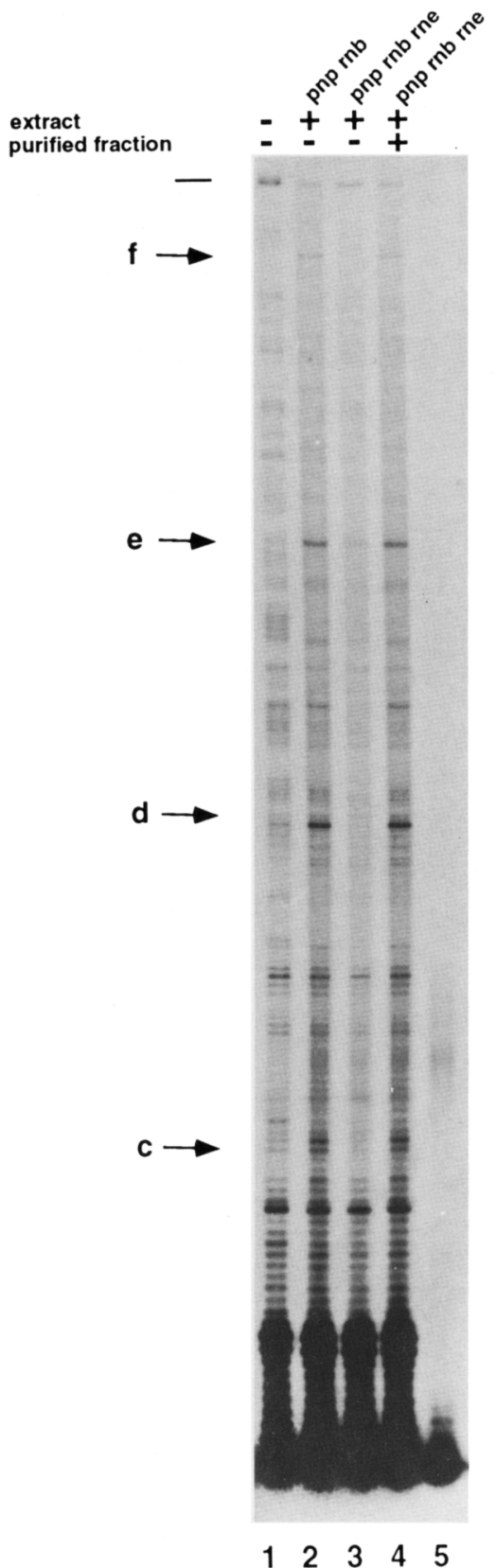

Figure 3. Several rne-dependent cleavages are present in the upstream region. Cold RNA obtained in vitro from plasmid pGEM1293 (Materials and methods) was incubated with S30 extracts derived from strains SK5003 (pnp rnb) and SK572l (pnp $\mathrm{mb} \mathrm{rne}$ ). The cleavage products were analyzed by primer extension with the oligonucleotide (lane 5) shown in Fig. 1B. Untreated runoff transcript was incubated at $44^{\circ} \mathrm{C}$ for $5 \mathrm{~min}$ before the analysis (lane 1). The runoff transcript was incubated with SK5003 extract (lane 2), SK5721 extract (lane 3), RNase E-enriched fraction was added to SK5721 extract before incubation (lane 4). The bar indicates the full-length extended product. Arrows indicate the more prominent $m e$-dependent cleavage sites (c,d,e, and f).

the extract was derived from the triple mutant SK5721 (Fig. 3, lane 3) and were increased when the RNase E-en- riched fraction was added to the SK5721 extract before RNA treatment (Fig. 3, lane 4). The relative position of the $5^{\prime}$ ends of the cleavage products was deduced from sequence ladders run in parallel (data not shown) and is presented in Figure 1B. The $\mathrm{d}$ band corresponded to a cleavage site located in a single-stranded region immediately upstream from the cis-acting element (Fig. 1B) and was also detectable in vivo as a faint band in an S1 mapping assay (data not shown). This experiment proved the presence of multiple rne-dependent cleavage sites within and upstream of the cis-acting element.

Deletion of the cis-acting element causes a severe reduction of the 3900-nucleotide processed species (Alifano et al. 1992). The evidence provided above suggested a prominent role for this element in binding and subsequent cleavage mediated by RNase $\mathrm{E}$. We tested whether a canonical RNase $\mathrm{E}$ target region could substitute for the native element. The region harboring the RNase $\mathrm{E}$ target site of RNAI of plasmid ColEl (Tomcsanyi and Apirion 1985; Bouvet and Belasco 1992) was religated in the correct position within pUH912, a plasmid without the cis-acting element. The resulting plasmid, pUH999 (Fig. 4A), was introduced into parental strain SK5006, and the RNA produced was analyzed in an S1 mapping experiment using the HindIII probe (Fig. 1A) labeled at its $5^{\prime}$ end (Fig. 4B, lane 1). The comparison between the protection pattern of RNAs derived from strain SK5006 harboring the complete plasmid pUH1293 (Fig. 4B, lane 2) or the deleted plasmid pUH912 (Fig. 4B, lane 3), with that obtained from RNA derived from the same strain harboring the hybrid plasmid pUH999 (Fig. 4B, lane 4), showed that the processed species $(\alpha)$ was produced in an amount comparable to that obtained in the presence of the natural element. Therefore, it seems that the cisacting element is necessary for the formation of the 3900-nucleotide species simply because it is an RNase E target site and it can be replaced by a functionally equivalent RNA region.

\section{RNase P participates in the formation of the 3900 -} nucleotide processed species

The $5^{\prime}$ end of the processed species must be produced by an endonucleolytic cleavage. Because formation of the $\alpha$ species is not entirely rne dependent (Fig. 2), we examined its production in other endoribonuclease mutants. Formation of the 3900-nucleotide species was not affected in the RNase III ${ }^{-}$host HT115 (data not shown), indicating that RNase III activity does not participate in the processing event.

Next, we tested the influence of RNase P on the formation of the stable species $\alpha$. We used strains harboring mutations affecting either the C5 protein (A49) or the M1 RNA subunit (ts709) (Schedl and Primakoff 1973; Kole et al. 1980; Guerrier-Takada et al. 1983). Cells containing the rnpA49 mutation do not grow at temperatures above $42^{\circ} \mathrm{C}$. However, even under permissive growth conditions, the activity of RNase P is considerably reduced in cells bearing this mutation /Schedl and Primakoff 1973). We therefore transformed the parental 
A

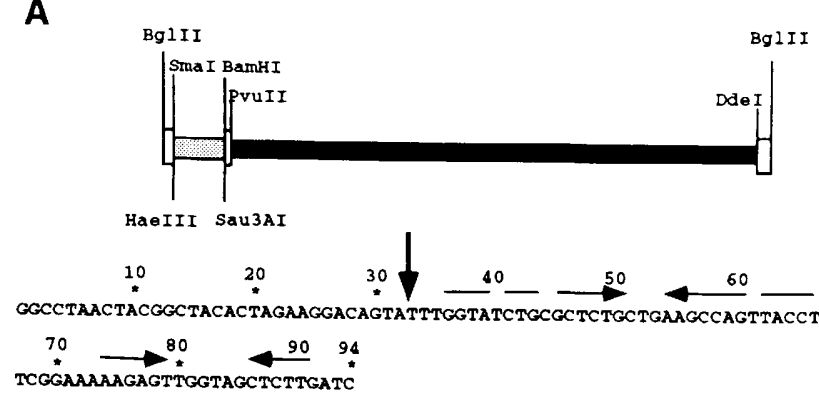

B

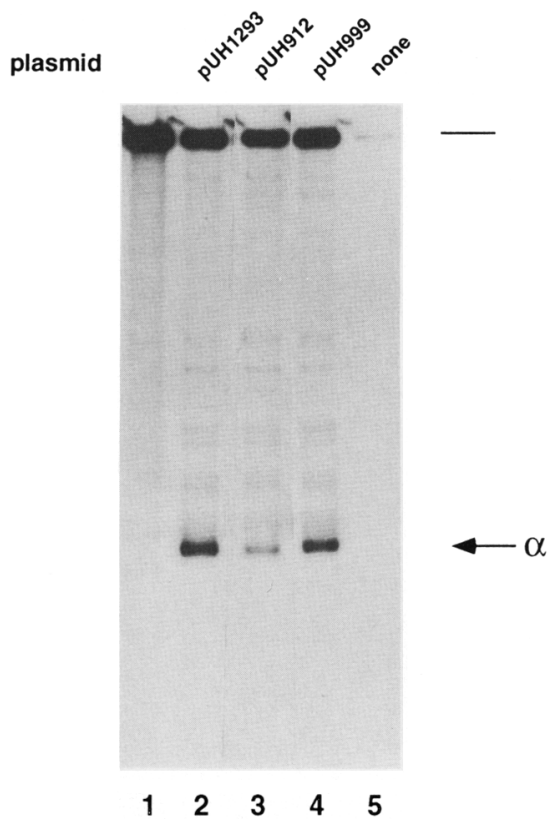

Figure 4. The region containing the ColE 1 me-dependent site can substitute for the upstream cis-acting element. $\langle A|$ The boxes indicate the different fragments used to construct the pUH999 hybrid plasmid (iopen) polylinker of the pUH912 plasmid; (shaded), fragment spanning the rne-dependent site of ColEl (Bouvet and Belasco 1992); (solid), PvuII-DdeI insert carried by pUH912 (Alifano et al. 1992)]. Relevant restriction sites used for the construction are indicated at the top. (Bottom) The sequence of the fragment derived from ColEl with its potential secondary structures (convergent arrows). The vertical arrow indicates the rne-dependent cleavage site. (B) Total RNA $(20 \mu \mathrm{g})$ extracted from strain SK5006 (lane 5) harboring the recombinant plasmids pUH1293 (lane 2), pUH912 (lane 3) and pUH999 (lane 4) was hybridized to the probe (Fig. 1A), labeled at its 5' end (lane 1), and analyzed as in Fig. 2 in an Sl protection assay. The bar indicates the full-length extended product, and the arrow the $5^{\prime}$ end of the 3900 -nucleotide processed species $|\alpha|$.

strain BF265 and its congenic derivative A49 (mpA49) with the plasmid pUH1293 and grew them at $37^{\circ} \mathrm{C}$. The parental strain 4273 and its congenic derivative ts 709 [mpB709(Ts)] were transformed with the same plasmid and grown at $30^{\circ} \mathrm{C}$ to logarithmic phase, after which onehalf of each culture was shifted to $44^{\circ} \mathrm{C}$ for $40 \mathrm{~min}$. RNAs derived from the transformed strains were ana- lyzed by $\mathrm{S} 1$ mapping by use of the HindIII fragment (Fig. 1A) labeled at its $5^{\prime}$ end as a probe (Fig. 5A, lane 1). Compared with BF265 (Fig. 5A, lane 2) in mutant strain A49 a decreased amount of the $\alpha$-processed species and a concurrent increase in the amount of full-length protected hybrids were detected. Accumulation of the intermediate rne-dependent $\mathrm{a}$ and $\mathrm{b}$ species was also observed (Fig. 5A, lane 3). Similar results were obtained when strain $\mathrm{A} 49$ was grown at $30^{\circ} \mathrm{C}$ and then shifted to $44^{\circ} \mathrm{C}$ (data not shown). The $\alpha$ band was present in strain 4273 grown at $30^{\circ} \mathrm{C}$ or shifted to $44^{\circ} \mathrm{C}$ (Fig. $5 \mathrm{~A}$, lanes 4,5 ). In mutant strain ts 709 there was an increase of the fulllength protected fragment. The $\alpha$ species almost disappeared at the nonpermissive temperature (Fig. 5A, lane 6) and was very faint even at the permissive temperature (Fig. 5A, lane 7). The different amount of his-specific transcripts could be attributable to the different genetic background of the parental and derivative strains.

Further proof of the involvement of RNase $\mathrm{P}$ in the processing event was obtained by an in vitro degradation assay. A 183-nucleotide-long labeled RNA (Fig. 5B, bottom, lane 1), obtained by in vitro transcription of the recombinant linearized plasmid pGEM322 (Fig. 5B, top; Materials and methods), was incubated at $44^{\circ} \mathrm{C}$ for 20 min with S30 and S100 extracts obtained from strains BF265 and A49. Formation of the processed species $(\alpha)$ was drastically reduced after incubation with mutant (Fig. 5B, bottom, lane 3) S30 extracts compared with the parental (Fig. 5B, bottom, lane 2) ones. The activity responsible for the processing of the substrate was only recovered in the S30 fraction, because formation of the $\alpha$ species was severely affected when the riboprobe was incubated with parental (Fig. 5B, bottom, lane 4), and more so with mutant (Fig. 5B, bottom, lane 5), S100 extracts. Similar results were obtained when cold RNA from plasmid pGEM322 was primer extended with a $5^{\prime}$ end-labeled oligonucleotide after incubation with the different extracts (data not shown). Next, we performed a reconstitution experiment by adding a purified preparation of RNase P (kindly provided by Dr. S. Altman, Yale University, New Haven, CT) to S30 extracts of parental and mutant strains (Fig. $5 \mathrm{C}$ ). Addition of the pure enzyme to the $\mathrm{S} 30$ extract prepared from mutant strain $\mathrm{A} 49$ restored processing of the labeled substrate (Fig. 5C, lane 5) as evidenced by the presence of the $\alpha$ species in amounts comparable with those detected with S30 extracts derived from parental strain BF265 in the absence (Fig. 5C, lane 2) or presence (Fig. 5C, lane 4) of the purified RNase P preparation. However, when the purified $E$. coli RNase $\mathrm{P}$ was directly challenged in vitro under the appropriate conditions with the same 183-nucleotide substrate, in the absence of any other component of the cellular extract, cleavage did not occur at all (Cecilia Guerrier-Takada, pers. comm.).

Ribosomes initiating at the intercistronic barrier hisC/hisB are necessary for the formation of the processed transcript

By use of drugs inhibiting the translation initiation step, 
Figure 5. Efficient formation of the 3900 nucleotide species requires active RNase $P$ and components of the S30 fraction. $|A|$ Total RNA $(20 \mu \mathrm{g})$ derived from strains harboring the plasmid pUH1293 was hybridized to the probe (Fig. 1A), labeled at the $5^{\prime}$ end (lane 1), and analyzed as in Fig. 2. Strain BF265 (lane 2) and its A49 (mpA49) derivative (lane 3) were grown at $37^{\circ} \mathrm{C}$; strain 4273 and its ts 709 derivative (rnpB709) were grown at $30^{\circ} \mathrm{C}$ (lanes 5,7 ) or shifted to $44^{\circ} \mathrm{C}$ (lanes 4,6 ). The bar indicates the full-length protected probe, and the arrows the $5^{\prime}$ ends of the processed species $(b, a$, and $\alpha)$. The arrowhead at left indicates the hybrid formed by transcripts initiating at the internal $\mathrm{P} 2$ promoter $(\mathrm{Al}$ ifano et al. 1992). (B) (Top) The boxes indicate the different fragments used to construct the pGEM322 hybrid plasmid [|solid) polylinker of the pGEM3Z vector plasmid; (shaded, far left) region of the $T 7$ promoter; (arrow) transcription initiation site; (open) DraI-HindIII 322-bp insert de

rived from the his $C /$ his $B$ region]. Relevant restriction sites used for the construction, and the internal Ncil site used to linearize the plasmid for in vitro transcription are indicated. (Bottom) Labeled RNA (lane 1) obtained in vitro from plasmid pGEM322 (Materials and methods) was incubated with S30 extracts derived from strains BF265 (lane 2) and A49 (lane 3), and with S100 extracts derived from strains BF265 (lane 4) and A49 (lane 5). (C) Labeled RNA (lane 1) obtained in vitro from plasmid pGEM322 (Materials and methods) was incubated with S30 extracts derived from strains BF265 and A49 in the absence (lanes 2,3) and in the presence (lanes 4,5) of purified RNase $\mathrm{P}$. The cleavage products were analyzed on a $6 \%$ polyacrylamide-urea denaturing gel. The bar indicates the full-length RNA, and the arrow the $5^{\prime}$ end of the processed product $(\alpha)$.

we have shown previously that formation of the initiation complex at the hisB cistron plays a major role in the processing event (Alifano et al. 1992, 1994). Further proof was obtained with a mutation that directly affected translation initiation. A mutation that changed the AUG initiation codon of the hisB cistron to ACG was constructed by in vitro site-directed mutagenesis of plasmid pUH1293 (Materials and methods) to produce plasmid pUH1293mut. At the same time, the mutation changed the UGA stop codon of the his $C$ cistron to CGA, generating a his $C$ peptide with a 6-amino-acid carboxy-terminal extension (Fig. 6A,B). The truncated hisB-encoded peptide produced by pUH1293 (Fig. 6B, lane 1) was not detected when pUH1293mut was transcribed and translated with an S30 extract (Fig. 6B, lane 2). Total RNAs derived from strain SK5006 transformed with plasmids pUH1293 and pUH1293mut were hybridized to the HindIII 5'-end-labeled probe (Fig. 1A) and analyzed by S1 mapping. The protection pattern showed comparable amounts of protection of the entire probe with both RNAs, whereas the band corresponding to the processed species $\alpha$, present in discrete amount in the strain harboring pUH1293 (Fig. 6C, lane 1), was considerably reduced in the strain carrying pUH1293mut (Fig. 6C, lane 2). From these data we obtained a further and more direct demonstration that the presence of ribosomes initiating translation at the his $B$ cistron is important for the formation of the processed species.

\section{Discussion}

me-dependent endonucleolytic cleavages are necessary for the maturation of the 3900-nucleotide species

The data presented in this paper demonstrate that formation of the 3900-nucleotide processed species initiates with rne-dependent endonucleolytic cleavages at multiple internal sites within hisC. The amount of the processed transcript and of minor breakdown products was significantly reduced in the pnp $m b$ rne triple mutant at the nonpermissive temperature compared with the congenic pnp rnb double mutant in vivo (Fig. 2). Compared with the parental strain, the strain harboring pnp and $r n b$ mutations accumulated a larger amount of the processed species, and additional processing intermediates ( $a$ and $b$ in Fig. 2) were detected. This finding is consistent with previous reports on the stabilization of products in strains with defective $3^{\prime}$ exonucleases (Mackie 1989; Plamann and Stauffer 1990; Jain and Kleckner 1993|. It is believed that in a wild-type host, a significant fraction of transcripts is cleaved endonucleolytically at more than one site, and the resulting internal fragments are rapidly degraded from their $3^{\prime}$ ends (Jain and Kleckner 1993).

We have shown previously by an RNA binding-shift assay that the cis-acting element needed for generation of the stable 3900-nucleotide species consists of an RNA 


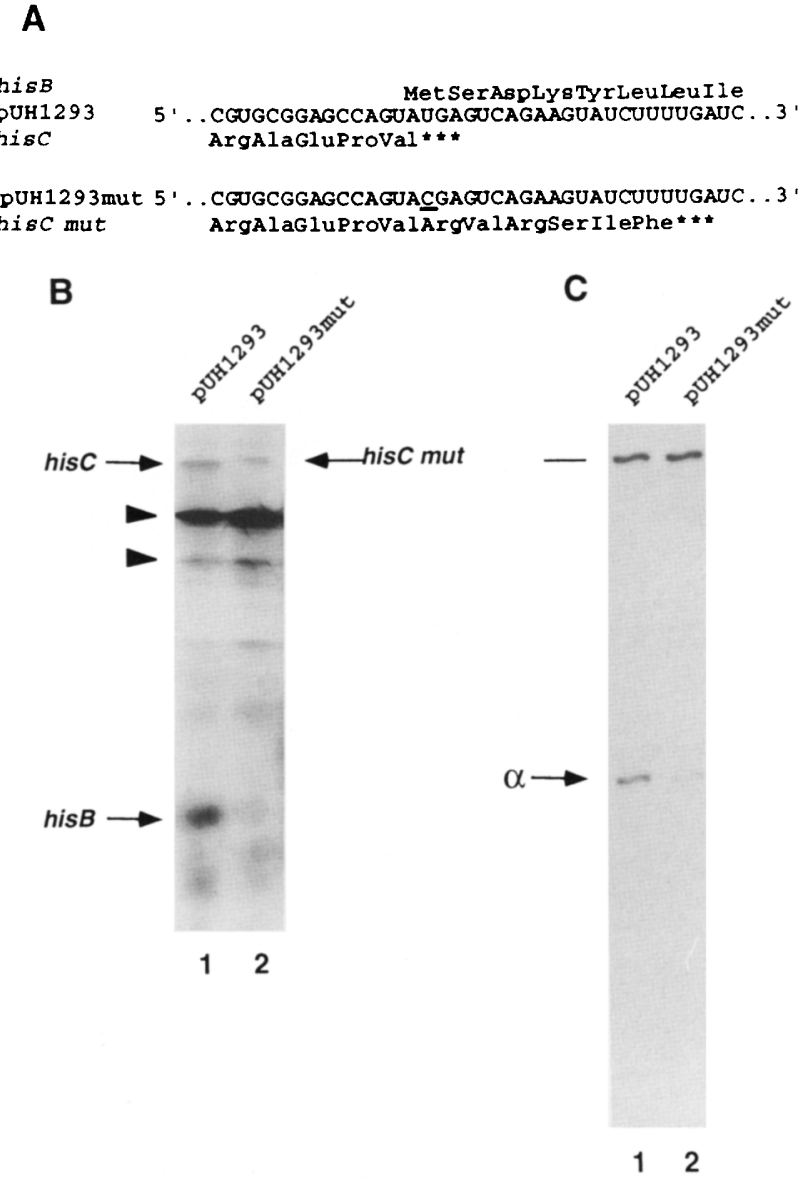

Figure 6. The uncoupling of translation at the intercistronic boundary his $C /$ his $B$ affects the maturation of the 3900-nucleotide species. (A) Effects of the mutation introduced in pUH1293mut on the translation product of his $C$ and his $B$ cistrons. For pUH1293 the sequence is indicated in the middle, the amino acid sequence of the his $B$ product is indicated at the top, and that of the his $C$ product at the bottom. For pUH1293mut, the nucleotide sequence is indicated on the top and the amino acid sequence of the fused his C/hisB peptide at the bottom. The mutated $C$ nucleotide in the intercistronic barrier is underlined. (B) Analysis on a $12 \%$ SDS-polyacrylamide gel of the peptides produced in a transcription-translation coupled system by the recombinant plasmids pUH1293 (lane 1) and pUH1293mut (lane 2). Arrowheads indicate the position of the $\beta$-lactamase peptides; arrows indicate the positions of the his-specific gene products. $(C)$ Total RNA $(20 \mu \mathrm{g})$ derived from strain SK5006 transformed with pUH1293 and pHU1293mut (lanes 1,2) was analyzed as in Fig. 2. The bar indicates the full-length protected probe, and the arrow the $5^{\prime}$ end of the mature species $|\alpha|$.

region that is able to bind soluble factor(s) in S30 extracts (Alifano et al. 1992). We have now observed that the binding activity was absent in extracts derived from the rne1 mutant strain and was present in a wild-type RNase E-enriched fraction. In this study we demonstrate that a different rne-dependent site, harboring only one RNase E target (Bouvet and Belasco 1992), can substitute for the region spanning the multiple RNase E sites (Fig. 4).
These evidences confirm that the formation of the mature species is an rne-dependent process, requiring at least one target site upstream of the $5^{\prime}$ end. The cleavage site (d) identified in the in vitro degradation assay (Fig. 3) is located immediately upstream of the putative stemloop structure corresponding to the cis-acting element and cleavage occurs at a degenerate consensus sequence GU/AUG for RNase E (Mackie 1991). Detection of the processing intermediate produced by this cleavage in vivo is difficult, probably because of its instability even in a pnp $m b$ background (see Results). The additional cleavage sites identified in vitro in the region of the element (c, e, and f) do not appear to play a major role in vivo. Deletion of these cleavage signals does not affect significantly the production of the 3900-nucleotide processed species (Alifano et al. 1992). It is possible that a hierarchy of target sites exists in vivo, depending on their consensus. Alternatively, these multiple target sites might be less accessible to RNase $\mathrm{E}$ in vivo because of interference by translating ribosomes.

\section{RNase P participates in the maturation of the 3900-nucleotide species}

Alternative mechanisms can be proposed for the production of the 3900-nucleotide processed transcript by medependent cleavage of an upstream region. (1) The upstream cis-acting element serves as an entry site for a processive endoribonuclease uniquely responsible for the maturation event. It has been proposed that a $5^{\prime}$ binding endonuclease exists in $E$. coli that is capable of binding the $5^{\prime}$ end of mRNA molecules and migrating or looping downstream until a recognition site for endonucleolytic cleavage is encountered (Bouvet and Belasco 1992; Di Mari and Bechhofer 1993). Given its involvement in the decay of many mRNAs, RNase E has been suspected to be this enzyme. In our system we cannot conclude that RNase $\mathrm{E}$ is the only activity involved and that it works exclusively with this intrinsic $5^{\prime} \rightarrow 3^{\prime}$ processivity. We observed that deletion of the cleavage sites $c-f$ did not impede cleavage at the downstream a and b rne-dependent sites (data not shown) and reduced but did not abolish production of the processed species $(\alpha)$ (Fig. 4; Alifano et al. 1992). (2) The initial cleavage at the upstream element might trigger downstream decay by a $5^{\prime}$ exonuclease that is temporarily arrested at the stemloop structure at the $5^{\prime}$ end of the mature 3900-nucleotide species. However, no 5 ' exonucleolytic activities have been isolated from $E$. coli up until now (Petersen 1992). (3) Another endonuclease acting on substrates originated by $r n e$-dependent cleavages might be involved in generation of the mature 3900-nucleotide species. RNase E-inactivating cleavages have been reported in translated segments of many mRNAs (McCarthy et al. 1991; Klug 1993). The initial cleavages by RNase E functionally inactivate the mRNA molecules, leaving them unprotected by ribosomes as naked RNA and capable of forming structures recognized by other endonucleases. RNase III predominantly cuts untranslated regions of mRNAs, because of the higher order structure of the rec- 
ognition site that is impeded by translating ribosomes (Court 1993). In our system, the absence of RNase III did not cause a detectable effect on formation of the 3900nucleotide species.

Surprisingly, the amount of the 3900-nucleotide RNA was severely reduced in two hosts defective of the RNase $\mathrm{P}$ function (Fig. 5A). RNase $\mathrm{P}$ is an evolutionary conserved essential ribozyme and is required for the endonucleolytic cleavage of precursor tRNAs to generate the 5 ' termini of tRNA molecules (Altman 1990; Altman et al. 1993). In the attempt to define a minimal consensus sequence or RNA conformation recognized by this enzyme, it has been reported that any RNA could be targeted by a custom-designed external guide sequence (EGS) for specific cleavage by RNase $P$ in vivo or in vitro. It has been hypothesized that any RNA molecule that may fold into a short stem-loop structure followed by a $3^{\prime}$ distal NCCA consensus sequence might constitute a potential substrate for RNase $\mathrm{P}$ (Forster and Altman 1990). The 34-nucleotide sequence at the $5^{\prime}$ end of the processed 3900-nucleotide species seems to satisfy this requirement (Fig. 1B). A substrate comprising this sequence was also cleaved in vitro in the presence of wildtype but not of RNase P mutant S30 cellular extracts (Fig. 5B). According to previous findings indicating that RNase P cosediments with the ribosomes under the conditions used to prepare the extracts (Vioque et al. 1988), the activity responsible for cleavage of the substrate was predominantly recovered in the S30 and not in the $\mathrm{S} 100$ fraction. We can exclude the possibility that RNase P affects the processing event acting on RNase $E$ function. In the absence of a functional RNase $\mathrm{P}$, rne-dependent cleavages $(a$ and $b)$ located upstream of the final processing site $(\alpha)$ accumulated in vivo (Fig. $5 \mathrm{~A}$ ), similar to what was observed in the pnp $m b$ background. The reconstitution experiment with purified RNase $\mathrm{P}$ added to the mutant-derived S30 extract (Fig. 5C) excludes that lack of cleavage of the substrate is attributable to indirect effects of the rnp mutation on the composition and activity of the extract. These observations suggest that RNase P itself cleaves the substrate and support the hypothesis that RNase $\mathrm{P}$ acts on processing products generated by RNase E.

It has been reported that the $5^{\prime}$ end of a transcript plays a major role in determining the rate of its decay. Considerable stability is conferred by stem-loop structures sequestering the $5^{\prime}$ end of RNA molecules (Bouvet and Belasco 1992). RNase E, which controls the decay of many RNAs, cuts in single-stranded regions preceding stem-loop structures and leaves protruding $5^{\prime}$ ends, thus destabilizing the targeted molecules (Bouvet and Belasco 1992; Ehretsmann et al. 1992). On the contrary, cleavages of precursor molecules by RNase $P$ produce $5^{\prime}$ ends that are embedded in secondary structures (Altman 1990). We suggest that this may account for the relevant stability of the RNase P-dependent processed species.

We have shown previously that processing of the 3900nucleotide species requires binding of the ribosomes at the ribosomal binding site of hisB cistron in an in vitro system (Alifano et al. 1992). One might suspect that
RNase $\mathrm{P}$ affects the processing event by interfering with translation of his B. However, at least in the rnpA49 genetic background, translation rate is not significantly modified (Schedl and Primakoff 1973). In this study we showed that efficiency of the processing event producing the 3900-nucleotide species was severely reduced by a mutation disrupting both the termination codon of his $C$ and the initiation codon of hisB (Fig. 6). According to current models (Kozak 1983; Alifano et al. 1988), both ribosomal binding and initiation of translation of the his $B$ cistron are impeded in this mutant and this may alter the conformation of the intermediates produced by rne-dependent cleavages. This explanation supposes that the substrate for $r n p$-dependent cleavage must fold into the appropriate structure. Ribosomes initiating translation of the his $B$ cistron might favor the formation of the rnp-targeted structure, allowing RNase $\mathrm{P}$ to cleave the mRNA efficiently. The requirement of ribosomes for the processing reaction may account for the failure of the purified RNase $P$ to cleave the substrate in vitro in the absence of other components of the cellular extract $\mid \mathrm{C}$. Guerrier-Takada, pers. comm.; see Results) and for the ability of purified RNase $\mathrm{P}$ added to mutant-derived S30 extract to restore processing (Fig. $5 \mathrm{C}$ ).

The model proposed for the processing event of the his operon primary transcript leading to the production of the 3900-nucleotide species is shown in Figure 7. It may be articulated in the following steps: (1) RNase E (or an rne-controlled endonucleolytic activity/ cleaves the fulllength mRNA at multiple internal sites located within the his $C$ cistron. (2) Ribosomes translating the his $C$ cistron proceed until they reach the his $C /$ his $B$ intercistronic barrier, whereas the intermediate products are degraded by 3 ' exonucleases. (3) The $5^{\prime}$ region of the distal his RNA segment, produced by endonucleolytic cleavage, being uncovered by ribosomes, may assume an appropriate structure recognized by RNase P. Formation of this RNA structure is, in turn, dependent on ribosomes bound at the translation initiation site of the his $B$ cistron. (4) RNase P cleaves the targeted RNA at the bottom of the stem-loop structure located at the $5^{\prime}$ end of the 3900-nucleotide species. (5) The stem-loop structure that sequesters the $5^{\prime}$ end of the 3900-nucleotide species (Bouvet and Belasco 1992) and translation of the hisB cistron may be responsible for the considerable stability of this processed transcript.

\section{Materials and methods}

\section{Bacterial strains and plasmids}

The strains used in this study are listed in Table 1 . The strains were grown in minimal medium M9CA (Maniatis et al. 1982) supplemented with $0.5 \%$ glucose and $50 \mu \mathrm{g} / \mathrm{ml}$ of ampicillin as required.

Plasmids pUH1293, pUH912, and pGEM136 have been described previously (Alifano et al. 1992). Plasmid pGEM1293 was obtained by cloning in the Smal site of the polylinker of vector pGEM3Z (Promega) the insert carried by plasmid pUH1 293 (Fig. lA) in the correct orientation. Plasmid pGEM322 was constructed by insertion of a 322-bp DraI-HindIII fragment (Fig. 5B) 


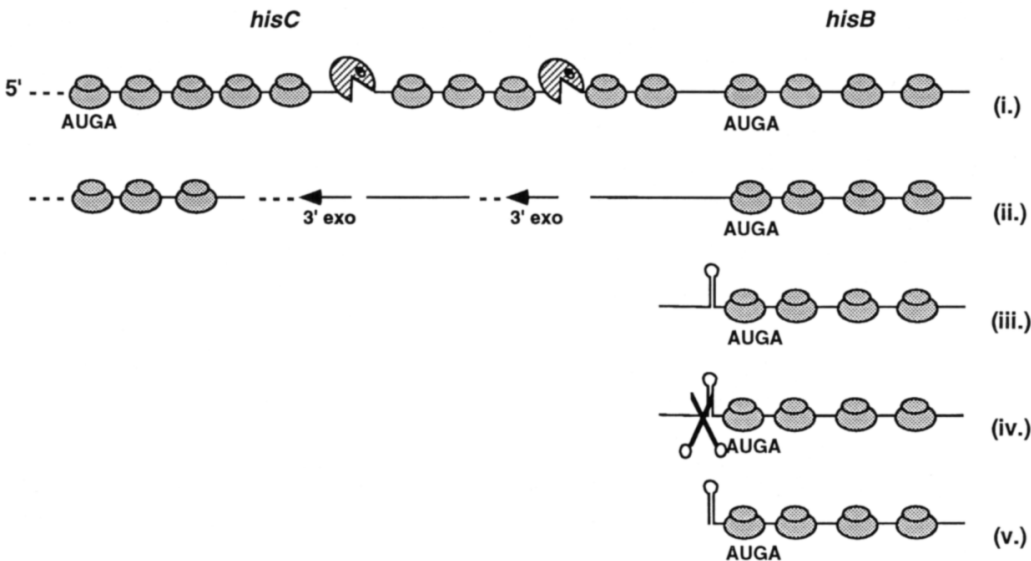

(i.) Figure 7. Model for the processing of the polycistronic his mRNA. The top drawing shows the active mRNA segment spanning the hisC and his $B$ cistrons with translating ribosomes. Two intemal cleavages by ribonuclease $\mathrm{E}$ (hatched forms) are also shown. The subsequent sequential steps are detailed in the Discussion. Arrows indicate the $3^{\prime} \rightarrow 5^{\prime}$ degradation of naked mRNA segments by $3^{\prime}$ exonucleases. The structure that forms at the $5^{\prime}$ end of the processed species in the presence of ribosomes bound at the his C/hisB intercistronic region (AUGA) is represented by a hairpin, which is then cleaved by ribonuclease $P$ (scissors) at the root of the stem-loop. into the polylinker of pGEM3Z digested with SmaI and HindIII. Plasmid pUH999 was constructed by ligation of a 94-bp HaeIIISau3AI fragment, spanning the RNase E target site of plasmid ColEl (Bouvet and Belasco 1992), into the polylinker of plasmid pUH912 digested with SmaI-BamHI. Plasmid pUH1293mut was obtained by site-directed mutagenesis (Kunkel et al. 1987) with a kit (Boehringer Mannheim) and the purified oligonucleotide 5'-GATACTTCTGACTCGTACTGGCTCCGCACG-3'. The construction was verified by DNA sequence analysis.

In vitro expression of plasmids pUH1293 and pUH1293mut was obtained in $\mathrm{S} 30$ extracts from $E$. coli, making use of a translation kit (Amersham) and following the instructions of the producer. We have indicated previously that the his $C$ cistron in plasmid pUH1293 was not translated, as it lacks the natural AUG start codon (Alifano et al. 1992). We have subsequently found that the cistron is translated at low efficiency starting from a GUG initiation codon (data not shown; Fig. 6B).

\section{DNA procedures}

Plasmid DNA was purified according to standard procedures (Sambrook et al. 1989). DNA fragments were isolated through acrylamide slab gels and recovered by electroelution (Sambrook et al. 1989). 5' End-labeling with polynucleotide kinase and nick translation were performed as described (Sambrook et al. 1989).

DNA sequencing was performed by the dideoxy chain termination procedure (Sanger et al. 1977). For the high-resolution S1 nuclease mapping experiments the ladder channels were obtained by the same procedure (Sanger et al. 1977).

\section{RNA preparation and hybridization procedures}

Total bacterial RNA was extracted from logarithmically growing cells by the guanidine hydrochloride procedure described previously (Grisolia et al. 1982).

RNA-DNA hybridization, S1 nuclease digestion, and analysis of the hybrids on polyacrylamide denaturing gels were performed with the same conditions described previously (Carlomagno et al. 1985). Because the strains that we used were his ${ }^{+}$, we ensured that his E.coli mRNA did not cross-hybridize to the S. typhimurium probe (Fig. 4B, lane 5).

\section{RNA-binding assays}

Crude (S30) extracts and RNase E-enriched ammonium sulfatefractionated extracts were prepared according to the procedure described by Mackie (1991), except that M9CA medium was employed in the bacterial growth.

The gel mobility retardation assays using a uniformly labeled RNA substrate derived from plasmid pGEM136 were performed as described previously (Alifano et al. 1992).

\section{In vitro degradation assays}

Plasmid pGEM1293 was linearized at the PstI site of the polylinker and transcribed in vitro in a reaction mixture containing $500 \mu \mathrm{M}$ each NTPs, $10 \mathrm{~mm}$ dithiothreitol, $40 \mathrm{~mm}$ Tris- $\mathrm{HCl} / \mathrm{pH}$ 7.5), $6 \mathrm{mM} \mathrm{MgCl} 2,2 \mathrm{~mm}$ spermidine, $10 \mu \mathrm{M} \mathrm{NaCl}$, and 5 units of T7 RNA polymerase (Boehringer) for $60 \mathrm{~min}$ at $38^{\circ} \mathrm{C}$. Template DNA was digested with $1 \mathrm{U} / \mu \mathrm{g}$ of DNA from RQ1 RNase-free DNase (Promega) and the RNA purified by phenol extraction and ethanol precipitation. One-tenth of the in vitro-made RNA was incubated with $\mathrm{S} 30$ extracts for $5 \mathrm{~min}$ at $44^{\circ} \mathrm{C}$ in a buffer containing $25 \mathrm{~mm}$ Tris- $\mathrm{HCl}$ (pH 8.5), $5 \mathrm{~mm} \mathrm{MgCl} 2,60 \mathrm{~mm} \mathrm{KCl}$, $100 \mathrm{mM} \mathrm{NH}_{4} \mathrm{Cl}, 0.1 \mathrm{~mm}$ dithiothreitol, $5 \%$ (wt $/ \mathrm{vol}$ ) glycerol, and $50 \mu \mathrm{g} / \mathrm{ml}$ of yeast RNA. The protein concentration was 1 $\mu \mathrm{g} / \mu \mathrm{l}$. The samples were extracted twice with a $1: 1$ mixture (vol/vol) of $0.1 \%$ SDS-saturated phenol and chloroform/isoamyl alcohol to eliminate contaminating proteins bound to RNA and then precipitated with $0.3 \mathrm{M} \mathrm{Na}$-acetate $(\mathrm{pH} 5)$ and 2.5 volumes of ethanol. The degradation products were then analyzed by primer extension as described by Fisher and Wray (1989) by use of a 40-nucleotide synthetic oligonucleotide complementary to the region underlined in Figure $1 \mathrm{~B}$.

Plasmid pGEM322 was linearized at the internal Ncil site (Fig. 7B) and transcribed in vitro, and the RNA was purified as described above except that the reaction mixture contained 100 $\mu \mathrm{M}$ ATP, CTP, and GTP, $10 \mu \mathrm{M}$ UTP, and $30 \mu \mathrm{Ci}$ of $\left[\alpha^{-32} \mathrm{P}\right] \mathrm{UTP}$ $(400 \mathrm{Ci} / \mathrm{mmole})$. $\mathrm{S} 30$ extracts were prepared according to Zubay (1973), and S100 fractions were obtained by ultracentrifugation of the $\mathrm{S} 30$ extracts for $45 \mathrm{~min}$ at $4^{\circ} \mathrm{C}$. One-twentieth of the in vitro made RNA was incubated with $\mathrm{S} 30$ or $\$ 100$ extracts for 20 min at $44^{\circ} \mathrm{C}$ in the buffer system described by Zubay (1973). The protein concentration was $1 \mu \mathrm{g} / \mu \mathrm{l}$. For the reconstitution experiment the RNase $\mathrm{P}$ holoenzyme was reassembled in vitro as described previously (Vioque et al. 1988). The degradation products were analyzed on $6 \%$ polyacrylamide denaturing gels.

\section{Acknowledgments}

We thank Dr. Cecilia Guerrier-Takada, who kindly offered to perform the in vitro experiment with $E$. coli-purified RNase P. We thank S. Altman for the generous gift of strains and S. Adhya 
for constructive criticisms and for providing strains. Special thanks go to Francesco D'Agnello for the preparation of illustrations. This work was partially supported by grants from Progetto Finalizzato Ingegneria Genetica of the Consiglio Nazionale delle Ricerche and by the Human Capital Mobility Programme founded by the Commission of the European Communities (grant CHRXCT930263) to M.S.C.

The publication costs of this article were defrayed in part by payment of page charges. This article must therefore be hereby marked "advertisement" in accordance with 18 USC section 1734 solely to indicate this fact.

\section{References}

Alifano, P., M.S. Ciampi, A.G. Nappo, C.B. Bruni, and M.S. Carlomagno. 1988. In vivo analysis of the mechanisms responsible for strong transcriptional polarity in a "sense" $\mathrm{mu}$ tant within an intercistronic region. Cell 55: 351-360.

Alifano, P., C. Piscitelli, V. Blasi, F. Rivellini, A.G. Nappo, C.B. Bruni, and M.S. Carlomagno. 1992. Processing of a polycistronic mRNA requires a $5^{\prime}$ cis element and active translation. Mol. Microbiol. 6: 787-798.

Alifano, P., F. Rivellini, A.G. Nappo, C.B. Bruni, and M.S. Carlomagno. 1994. Alternative patterns of his operon transcription and mRNA processing generated by metabolic perturbation. Gene 146: 15-21.

Altman, S. 1990. Ribonuclease P. I. Biol. Chem. 265: 20053 20056.

Altman, S., L. Kirschbom, and S. Talbot. 1993. Recent studies of ribonuclease P. FASEB I. 7: 7-14.

Arraiano, C.M., S.D. Yancey, and S.R. Kushner. 1988. Stabilization of discrete mRNA breakdown products in ams pnp $\mathrm{mb}$ multiple mutants of Escherichia coli K-12. I. Bacteriol. 170: 4625-4633.

Arraiano, C.M., S.D. Yancey, and S.R. Kushner. 1993. Identification of endonucleolytic cleavage sites involved in decay of Escherichia coli trxA mRNA. I. Bacteriol. 175: 1043-1052.

Babitzke, P. and S.R. Kushner. 1991. The ams/altered mRNA stability/protein and ribonuclease $E$ are encoded by the same structural gene of Escherichia coli. Proc. Natl. Acad. Sci. 88: $1-5$.

Babitzke, P., L. Granger, J. Olszewski, and S.R. Kushner. 1993. Analysis of mRNA decay and rRNA processing in Escherichia coli multiple mutants carrying a deletion in RNaseIII. $J$. Bacteriol. 175: 229-239.

Bouvet, P. and J.G. Belasco. 1992 Control of RNase E-mediated RNA degradation by 5 -terminal base pairing in E. coli. $\mathrm{Na}$ ture 360: 488-491.

Brun, Y.V., H. Sanfaçon, R. Breton, and I. Lapointe. 1990. Closely spaced and divergent promoters for an aminoacyltRNA synthetase gene and a tRNA operon in Escherichia coli. J. Mol. Biol. 214: 845-864.

Carlomagno, M.S., A. Riccio, and C.B. Bruni. 1985. Convergently functional, Rho-independent terminator in Salmonella typhimurium. J. Bacteriol. 163: 362-368.

Carlomagno, M.S., L. Chiariotti, P. Alifano, A.G. Nappo, and C.B. Bruni. 1988. Structure and function of the Salmonella typhimurium and Escherichia coli K-12 histidine operons. I. Mol. Biol. 203: 585-606.

Carpousis, A.J., G. Van Houwe, C. Ehretsmann, and H.M. Krisch. 1994. Copurification of E. coli RNase E and PNPase: Evidence for a specific association between two enzymes important in RNA processing and degradation. Cell 76: 889900.

Court, D. 1993. RNA processing and degradation by RNase III. In Control of messenger RNA stability (ed. G.J. Belasco and
G. Brawerman|, pp. 71-116. Academic Press, San Diego, CA. Deutscher, M.P. 1988. The metabolic role of RNases. Trends Biochem. Sci. 13: 136-139.

Di Mari, J.F. and D.H. Bechhofer. 1993. Initiation of mRNA decay in Bacillus subtilis. Mol. Microbiol. 7: 705-717.

Donovan, W.P. and S.R. Kushner. 1986 Polynucleotide phosphorylase and ribonuclease II are required for cell viability and mRNA turnover in Escherichia coli K-12. Proc. Natl. Acad. Sci. 83: 120-124.

Ehretsmann, C.P., A.J. Carpousis, and H.M. Krisch. 1992. Specificity of Escherichia coli endoribonuclease $\mathrm{E}$ : in vivo and in vitro analysis of mutants in a bacteriophage T4 mRNA processing site. Genes \& Dev. 6: 149-159.

Faubladier, M., K. Cam, and J.-P. Bouche. 1990. Escherichia coli cell division inhibitor DicF-RNA of the $\operatorname{dicB}$ operon. Evidence for its generation in vivo by transcription termination and by RNase III and RNase E-dependent processing. I. Mol. Biol. 212: 461-471.

Fisher, S.H. and L.V. Wray. 1989. Regulation of glutamine synthetase in Streptomyces coelicolor. I. Bacteriol. 173: 23782383.

Forster, A.C. and S. Altman. 1990. External guide sequences for an RNA enzyme. Science 249: 783-786.

Ghora, B.K. and D. Apirion. 1978 Structural analysis and in vitro processing to p5 rRNA of a 9S RNA molecule isolated from an me mutant of $E$. coli. Cell 15: 1055-1066.

Grisolia, V., M.S. Carlomagno, and C.B. Bruni. 1982. Cloning and expression of the distal portion of the histidine operon of Escherichia coli K-12. J. Bacteriol. 151: 692-700.

Gross, G. 1991. RNase E cleavage in the atpE leader region of atp/interferon $\beta$ transcripts in Escherichia coli causes enhanced rates of mRNA decay. 7 . Biol. Chem. 266: 1788017884.

Guerrier-Takada, C., K. Gardiner, T. Marsh, N. Pace, and S. Altman. 1983. The RNA moiety of ribonuclease P is the catalytic subunit of the enzyme. Cell 35: 849-857.

Jain, C. and N. Kleckner. 1993. IS10 mRNA stability and steady state levels in Escherichia coli: Indirect effects of translation and role of rne function. Mol. Microbiol. 9: 233-247.

Klug, G. 1993. The role of decay of mRNA degradation in the regulated expression of bacterial photosynthesis genes. Mol. Microbiol. 9: 1-7.

Kokoska, R.J., K.J. Blumer, and D.A. Steege. 1990. Phage fl mRNA processing in Escherichia coli: Search for the upstream products of endonuclease cleavage, requirement for the product of the altered mRNA stability (ams) locus. Biochimie 72: 803-811.

Kole, R., M.F. Baer, B.C. Stark, and S. Altman. 1980. E. coli RNase $\mathrm{P}$ has a required RNA component in vivo. Cell 19: $881-887$.

Kozak, M. 1983. Comparison of initiation of protein synthesis in procaryotes, eucaryotes, and organelles. Microbiol. Rev. 47: $1-45$.

Kunkel, T.A., J.D. Roberts, and R.A. Zakour. 1987. Rapid and efficient site-specific mutagenesis without phenotypic selection. Methods Enzymol. 154: 367-382.

Lin-Chao, S. and S.N. Cohen. 1991 The rate of processing and degradation of antisense RNAI regulates the replication of ColEI-type plasmids in vivo. Cell 65: 1233-1242.

Mackie, G.A. 1989. Stabilization of the 3' one-third of Escherichia coli ribosomal protein S20 mRNA in mutants lacking polynucleotide phosphorylase. I. Bacteriol. 171: 4112-4120.

- 1991. Specific endonucleolytic cleavage of the mRNA for ribosomal protein $\mathrm{S} 20$ of Escherichia coli requires the product of the ams gene in vivo and in vitro. J. Bacteriol. 173: 2488-2497. 
Maniatis, T., E.F. Fritsch, and I. Sambrook. 1982. Molecular cloning: A laboratory manual. Cold Spring Harbor Laboratory, Cold Spring Harbor, New York.

McCarthy, J.E.G., B. Gerstel, B. Surin, U. Wiedemann, and P. Ziemke. 1991. Differential gene expression from the Escherichia coli atp operon mediated by segmental differences in mRNA stability. Mol. Microbiol. 5: 2447-2458.

Mudd, E.A. and C.F. Higgins. 1993. Escherichia coli endoribonuclease RNase E: Autoregulation of expression and sitespecific cleavage of mRNA. Mol. Microbiol. 9: 557-568.

Mudd, E.A., P. Prentki, D. Belin, and H.M. Krisch. 1988. Processing of unstable bacteriophage T4 gene 32 mRNA into a stable species requires Escherichia coli ribonuclease E. EMBO I. 7: 3601-3607.

Mudd, E.A., A.J. Carpousis, and H.M. Krisch. 1990a. Escherichia coli RNase $\mathrm{E}$ has a role in the decay of bacteriophage $\mathrm{T} 4$ mRNA. Genes \& Dev. 4: 873-881.

Mudd, E.A., H.M. Krisch, and C.F. Higgins. 1990b. RNase E, an endoribonuclease, has a general role in the chemical decay of E. coli mRNA: Evidence that $r n e$ and ams are the same genetic locus. Mol. Microbiol. 4: 2127-2135.

Nilsson, P. and B.E. Uhlin. 1991. Differential decay of a polycistronic Escherichia coli transcript is initiated by RNaseEdependent endonucleolytic processing. Mol. Microbiol. 5: 1791-1799.

Patel, A.M. and S.D. Dunn. 1992. RNase E-dependent cleavages in the 5' and $3^{\prime}$ regions of the Escherichia coli unc mRNA. I. Bacteriol. 174: 3541-3548.

Petersen, C. 1992. Control of functional mRNA stability in bacteria: Multiple mechanisms of nucleolytic and non-nucleolytic inactivation. Mol. Microbiol. 6: 277-282.

Plamann, M.D. and G.V. Stauffer. 1990. Escherichia coli glyA mRNA decay: The role of 3 ' secondary structure and the effects of the pnp and mb mutations. Mol. Gen. Genet. 220: 301-306.

Rechler, M.M., C.B. Bruni, R.G. Martin, and W. Terry. 1972. An intercistronic region in the histidine operon of Salmonella typhimurium. I. Mol. Biol. 69: 427-452.

Régnier, P. and E. Hajnsdorf. 1991. Decay of mRNA encoding ribosomal protein S15 of Escherichia coli is initiated by an RNase E-dependent cleavage that removes the $3^{\prime}$ stabilizing stem and loop structure. J. Mol. Biol. 217: 283-292.

Reiner, A.M. 1969. Isolation and mapping of polynucleotide phosphorylase mutants of Escherichia coli. I. Bacteriol. 97: 1437-1443.

Sambrook, J., E.F. Fritsch, and T. Maniatis. 1989. Molecular cloning: A laboratory manual, 2nd ed. Cold Spring Harbor Laboratory Press, Cold Spring Harbor, New York.

Sanger, F., S. Nicklen, and A.R. Coulson. 1977. DNA sequencing with chain termination inhibitors. Proc. Natl. Acad. Sci. 74: 5463-5466.

Schedl, P. and P. Primakoff. 1973. Mutants of Escherichia coli thermosensitive for the synthesis of transfer RNA. Proc. Natl. Acad. Sci. 70: 2091-2095.

Takiff, H.E., S.-M. Chen, and D.L. Court. 1989. Genetic analysis of the rnc operon of Escherichia coli. I. Bacteriol. 171: 25812590.

Tomcsanyi, T. and D. Apirion. 1985. Processing enzyme ribonuclease E specifically cleaves RNA I. An inhibitor of primer formation in plasmid DNA synthesis. J. Mol. Biol. 185: 713720.

Vioque, A., J. Arnez, and S. Altman. 1988. Protein-RNA interaction in the RNase P holoenzyme from Escherichia coli. $I$. Mol. Biol. 202: 835-848.

Zubay, G. 1973. In vitro synthesis of protein in microbial systems. Annu. Rev. Genet. 7: 267-287. 


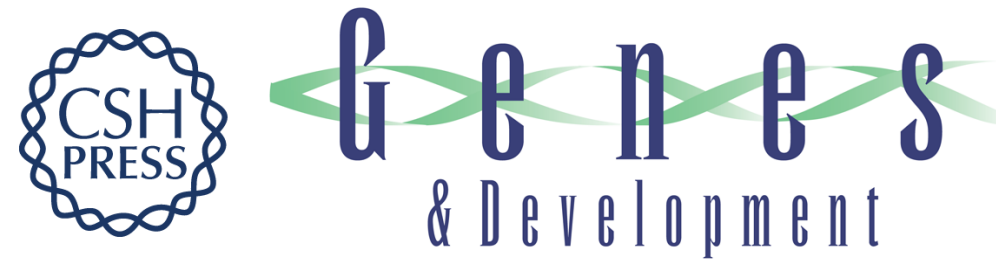

\section{Ribonuclease E provides substrates for ribonuclease P-dependent processing of a polycistronic mRNA.}

P Alifano, F Rivellini, C Piscitelli, et al.

Genes Dev. 1994, 8:

Access the most recent version at doi:10.1101/gad.8.24.3021

References This article cites 52 articles, 20 of which can be accessed free at:

http://genesdev.cshlp.org/content/8/24/3021.full.html\#ref-list-1

License

Email Alerting

Service

Receive free email alerts when new articles cite this article - sign up in the box at the top right corner of the article or click here.

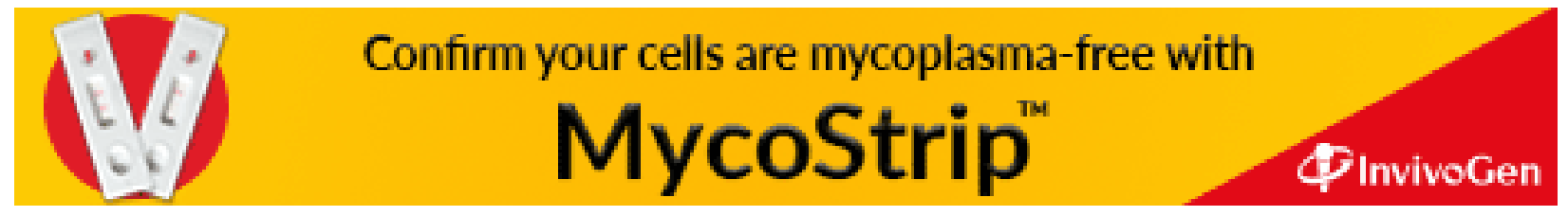

